\title{
Comparis of digital elevation model (DEM) and aerial photographs for drainage
}

\author{
Marzieh Mokarram ${ }^{1} \cdot$ Majid Hojati $^{2}$ (D)
}

Received: 4 November 2015/Accepted: 7 November 2015/Published online: 25 November 2015

(C) Springer International Publishing Switzerland 2015

\begin{abstract}
Currently, elevation data are available from several major sources and at different spatial resolutions. This paper shows the quality and accuracy of drainage network analysis resulted from ASTER DEMs and aerial photographs. Hydrology toolsets in the when we used the vector datasets for analyzing in separate land features. The agreement degree between two layers is very low for spatial pattern, river frequency and drainage density in lowland areas. ArcGIS package was used to extract drainage networks from a grid DEM for the study area in the northeastern of Iran. We have compared the extracted networks from DEM (DEM layer) and aerial photographs. Results showed that automated river extraction from ASTER DEMs is the best method for river extraction.
\end{abstract}

Keywords DEM analysis - Geomorphology $\cdot$ River network

\section{Introduction}

Many algorithms have been developed to derive basic topographic characteristics or features from DEMs, such algorithms include extracting drainage networks (Mark

Majid Hojati

majid.hojati@ut.ac.ir

Marzieh Mokarram

m.mokarram@shirazu.ac.ir

1 Department of Range and Watershed, College of Agriculture and Natural Resources of Darab, Shiraz University, Darab, Iran

2 MSc Student of Remote Sensing and GIS, Tehran University, Tehran, Iran
1984) and delineating watersheds (Band 1986; Donker 1992). Basic geomorphic or topographic attributes extracted from DEMs often serve as inputs to other models. Thus, DEMS and related algorithms provide the foundations of scientific in queries related to environment and topography. The degree of quality and accuracy of DEMS and the nature of algorithms are basic questions for above analysis. In another words relationships between resolutions and analysis results are often not quite simple. Kienzle shows that liner relationship exists between resolution and certain terrain derivatives such as slope, but not others (Kienzle 2004; Hosseinzadeh 2011).

Therefore in this paper we examined the quality and accuracy of aerial photographs and high resolution satellite images in the northeastern of Iran.

\section{Methods and materials}

\section{Study area}

The study area is located in the northeastern of Iran (Fig. 1), drains an area of $4,683 \mathrm{~km}^{2}$. The elevation of the study area is from 1,370 to $3,159 \mathrm{~m}$.

\section{Method}

The method employed to evaluation of degree adjustment between the drainage network extracted automatically from a DEM and the network delineation from photographs and satellite images comprises three steps: drawing rivers from aerial photographs and satellite images, automated delineation from an ASTER DEM by ArcGIS package and comparison of the two results in raster and vector formats (Hosseinzadeh 2011). 


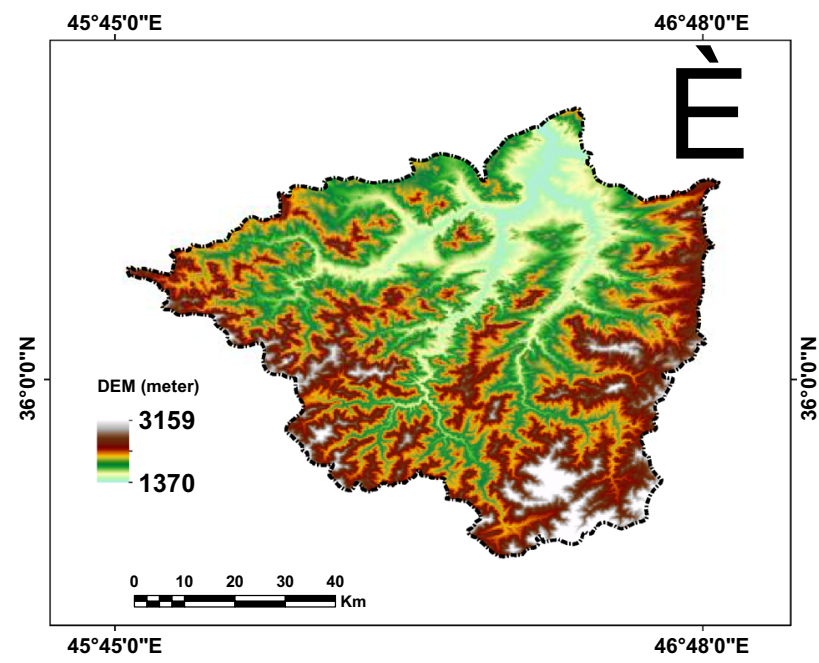

Fig. 1 Location of the study area

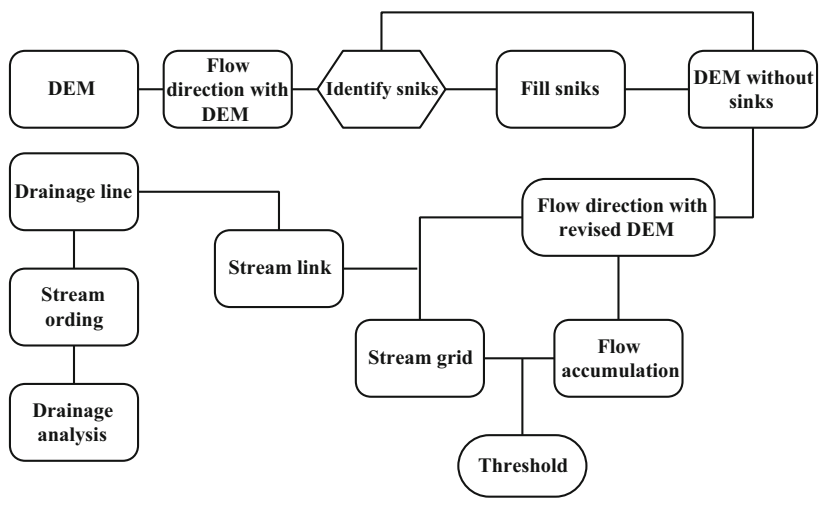

Fig. 2 Conceptual work flow for drainage network delineation ( $\mathrm{Li}$ and Wong 2010)

The river network of the study area was drawn from ASTER digital elevation model and photo interpretation of 1:20,000 scale aerial photographs for the time period of 2010. The criterion used to define first-order channels were they have channel morphology and a length of over $50 \mathrm{~m}$. River's network has been digitized by ArcGIS sketch tools after geometric transformation of image and aerial photographs in UTM coordinate system. This map has used as real ground to comprise the automated river network extraction in GIS method.
The extraction of the drainage network of the study area carried out from an ASTER DEM, in raster format with a $90 \mathrm{~m} \times 90 \mathrm{~m}$ grid cell size. Hydrological tools in ArcGIS software, version 10.3 was used to extract drainage channels. The automated method for delineating streams followed a series of steps (Fig. 2) starting with a filled DEM. The recognition of individual DEM cells as channel cells, where a cell is classified as a channel if certain cells surrounding it are higher than that cell (Torwaki and Fukumura 1978; Peunker and Douglas 1975; Douglas 1986). A common problem with drainage network delineation using DEM is the presence of sinks (Nikolakopoulos and Kamaratakis 2006), in fact the main problems are the positioning of the ends of drainage networks and the assignment of flow directions to individual cells, particularly in flat areas and depressions (Tribe 1992). A filled DEM is void of depressions. We used the fill function in the Hydrology toolset of ArcGIS software to remove the depressions to prepare sink. In the next step we made the flow direction raster. A flow direction raster shows the direction water will flow out of each cell of a filled DEM. This method used by ArcGIS, assigns a cell's flow direction to one of its eight surrounding cells that has the steepest distance weighted gradient (O'Callaghan and Mark 1984). Then we used the flow accumulation function in the ArcToolbox to extraction a flow accumulation raster which tabulates for each cell the number of cells that will flow to it. It records how many upstream cells will contribute drainage to each cell. Stream network and stream link delineation have been done in the next steps. This activity is based on a threshold accumulation value. A higher threshold value will result in a less dense stream network and fewer sub basins than a lower threshold value (Hosseinzadeh 2011). In the last stage, the rivers are ordered by Strahler method ordering and transformed to vector layer for further analysis. Morphometric parameters that analysis in the study area are shown in Table 1.

Obviously, both networks contain errors. For our comparison, we took the extracted networks from aerial photographs and images to be real stream channels. This is partly because the more detailed scale of the aerial photos and satellite images guarantees a good reference map with which to compare the network obtained from the DEM. The comparison process has been done in both raster and
Table 1 Area of the landform classes for each of the stream order from ASTER DEM

\begin{tabular}{llllllllllll}
\hline Stream order & \multicolumn{1}{l}{ Classes of the landform } \\
\hline Order & 1 & 2 & 3 & 4 & 5 & 6 & 7 & 8 & 9 & 10 \\
Order 1 & 85.32 & 0.24 & 0.14 & 4.24 & 0.31 & 0.12 & 0.25 & 5.68 & 0.83 & 2.87 \\
Order 2 & 84.93 & 0.04 & 0.22 & 4.17 & 0.26 & 0.13 & 0.30 & 7.08 & 0.83 & 2.04 \\
Order 3 & 91.84 & 0.04 & 3.13 & 0.00 & 0.16 & 0.08 & 0.04 & 4.22 & 0.08 & 0.41 \\
Order 4 & 89.67 & 0.07 & 0.03 & 4.61 & 0.07 & 0.03 & 0.07 & 3.74 & 0.35 & 1.35 \\
\hline
\end{tabular}


Fig. 3 The Rivers extracted from aerial photos and satellite images

Fig. 4 The Rivers extracted from DEM
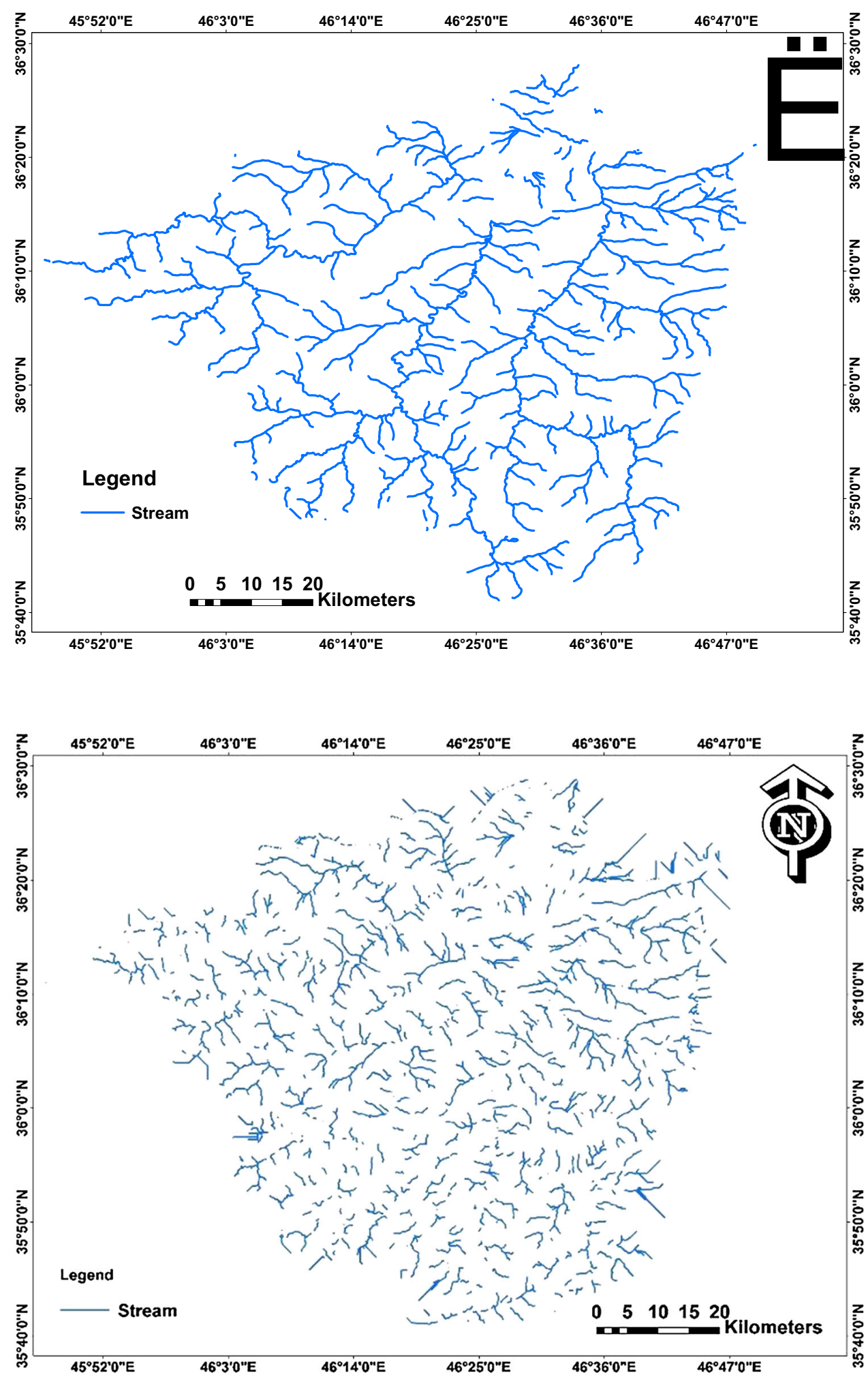

vector formats. These comparisons are included morphometric characteristics as the river frequency, stream length, stream density and drainage ratio as well as the spatial pattern of the drainage lines, which was evaluated by visual analysis and calculating the degree of coincidence between two networks. 
Fig. 5 Agreement degree $(\%)$ of spatial location between delineated networks from images in the pediment area ASTER DEM and satellite

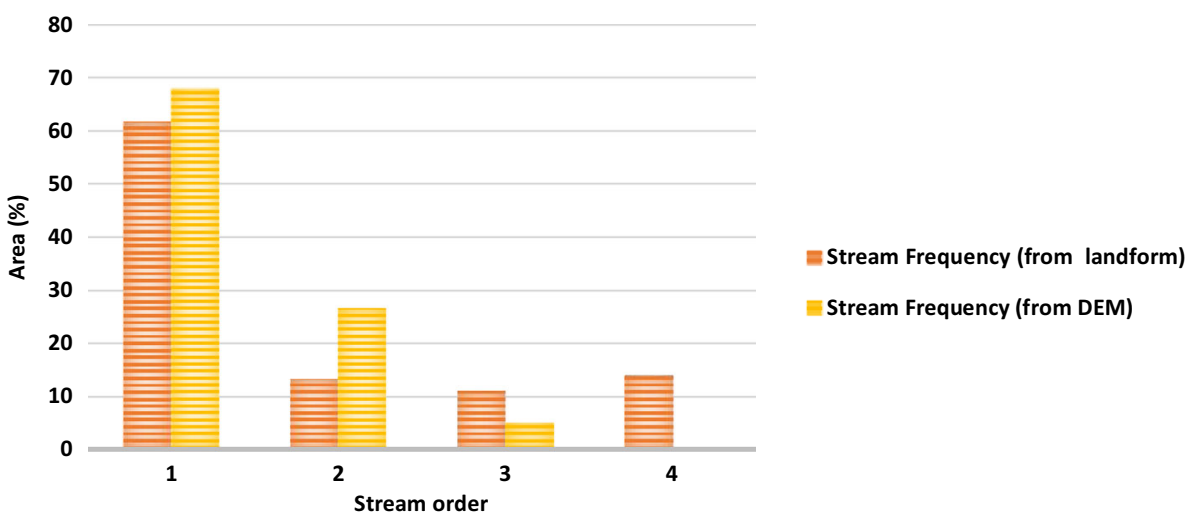

Fig. 6 The map of geomorphology units in the study area

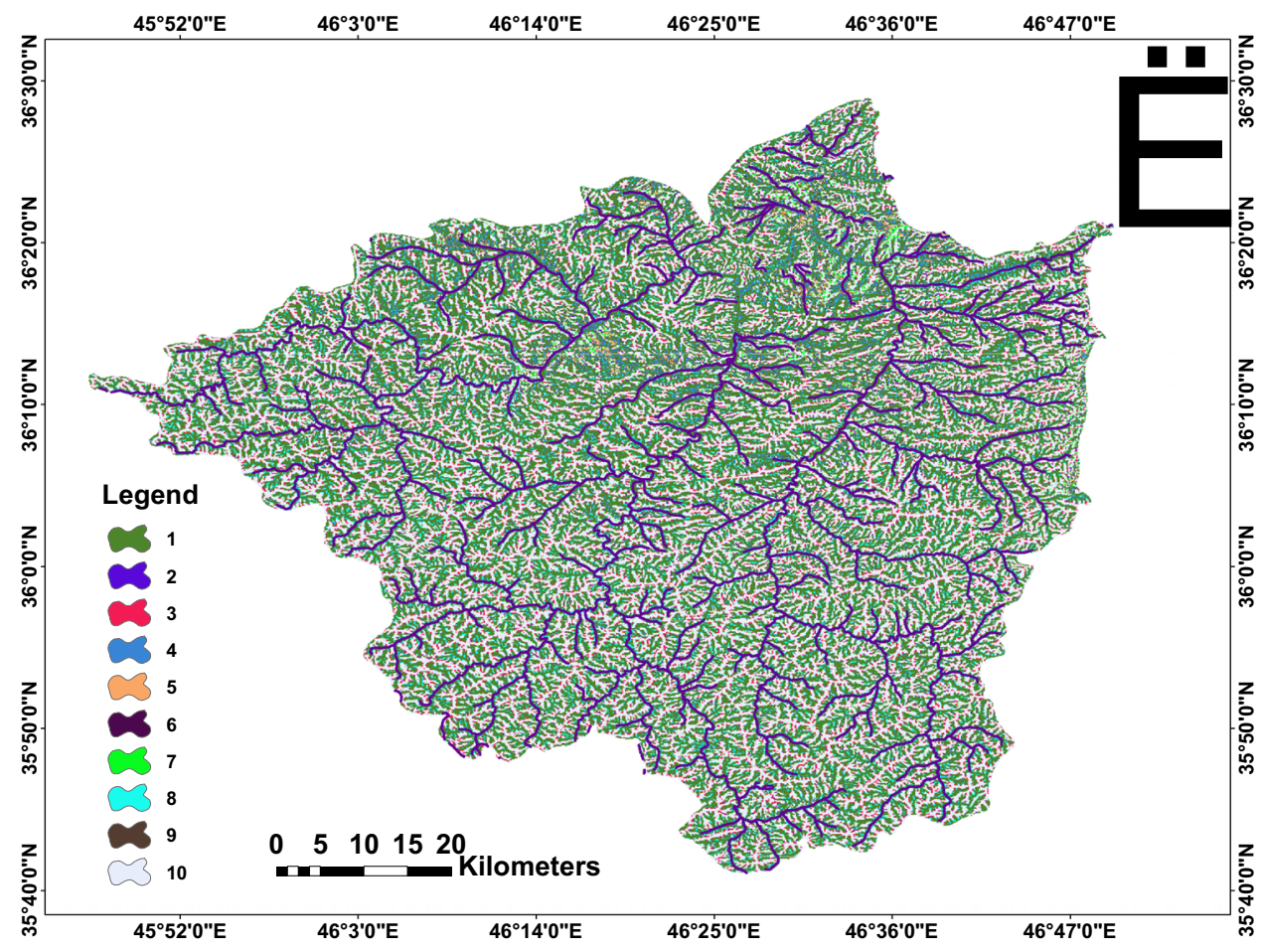

surrounding that cell. Positive values indicate that the cell is higher than its neighbors while negative values indicate the cell is lower (Weiss 2001). TPI values provide a simple and powerful means to classify the landscape into morphological classes (Jenness 2005). The areas of the classes is shown in Table 1 and Fig. 7.

\section{Conclusion}

The morphometric analysis based on extracted networks from ASTER DEMs is enough to derive river networks in the landform classes. It is possible to increase the threshold values for network extraction on the canyons/deeply incised streams (order 3), midslope drainages/shallow 
Fig. 7 Agreement degree of river frequencies (\%) between delineated networks from ASTER DEM and satellite images for landform

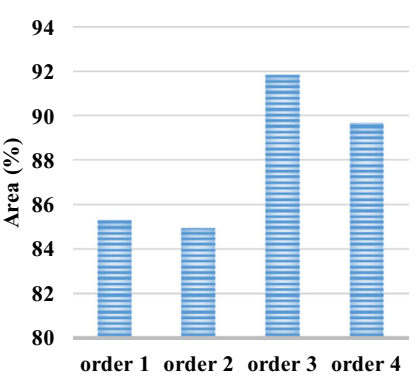

Canyons, Deeply Incised Streams

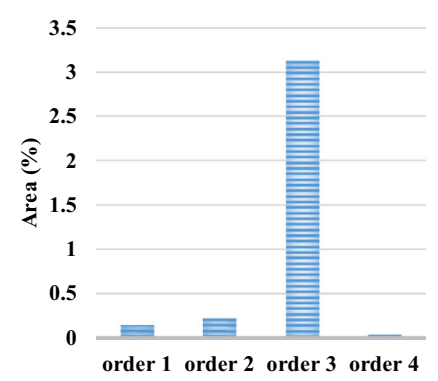

Upland Drainages, Headwaters
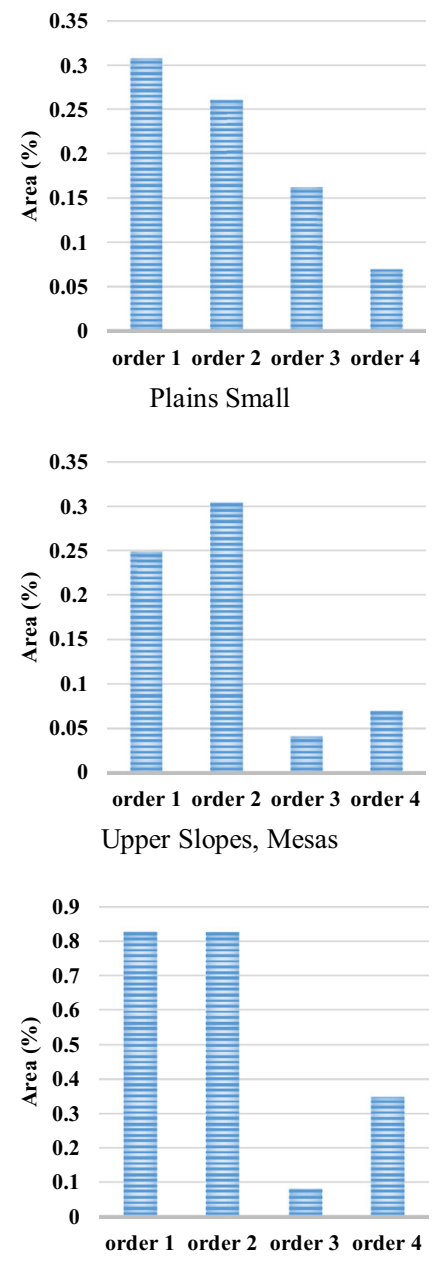

Mid slope Ridges, Small Hills in Plains

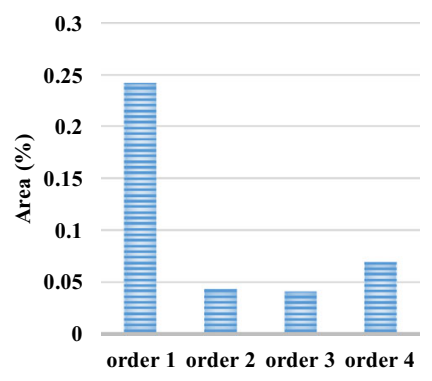

Midslope Drainages, Shallow Valleys

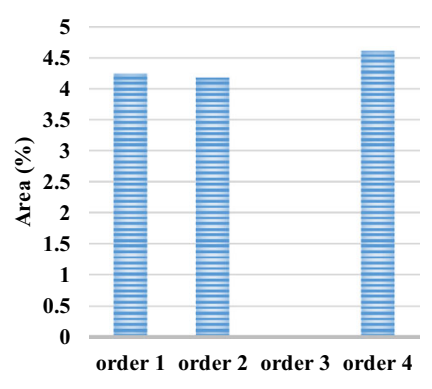

U-shaped Valleys
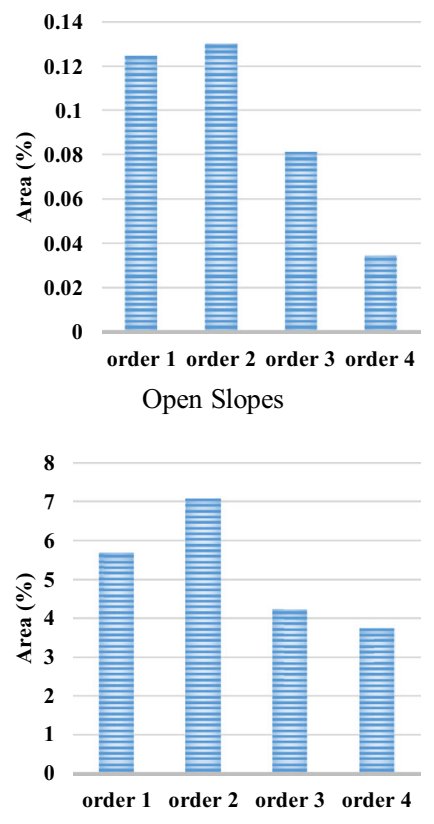

Local Ridges/Hills in Valleys

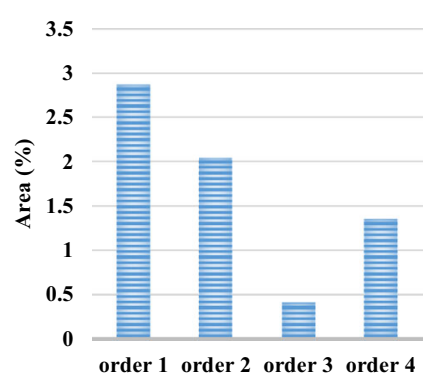

Mountain Tops, High Ridges 
valleys (order 1), upland drainages/headwaters (order 3), u-shaped valleys (order 4), plains small (order 1), open slopes (order 2), upper slopes/mesas (order 2), local ridges/ hills in valleys (order 2), mid slope ridges/small hills in plains (order 1), and mountain tops/high ridges (order 1). Therefore, the best method for river extraction can be using ASTER DEM.

\section{References}

Band LE (1986) Topographic partition of watersheds with digital elevation models. Water Resour Res 22:15-24

Donker N (1992) Automatic extraction of catchment hydrologic properties from digital elevation model. ITC J 3:257-265

Douglas PH (1986) Experiments to locate ridges and channels to create a new type of digital elevation model. Cartographica 23:29-61

Hosseinzadeh SR (2011) Drainage network analysis, comparis of digital elevation model (DEM) from ASTER with high resolution satellite image and areal photographs. Int J Environ Sci Dev 2(3):194-198
Jenness J (2005) Topographic position index (tpi_jen.avx) extension for ArcView 3.x. Jenness Enterprises. http://www.jennessent.com

Kienzle S (2004) The effect of DEM raster resolution on first order, second order and compound terrain derivatives. Trans GIS $8(1): 83-111$

Li J, Wong DWS (2010) Effects of DEM sources on hydrologic applications. Comput Environ Urban Syst 34:251-261

Mark DM (1984) Automatic detection of drainage networks from digital elevation models. Cartographia 21:168-178

Nikolakopoulos KG, Kamaratakis EK (2006) SRTM vs ASTER elevation products. Comparison for two regions in Crete, Greece. Int J Remote Sens 27(21):4819-4838. doi:10.1080/ 01431160600835853

O'Callaghan JF, Mark DM (1984) The extraction of drainage networks from digital elevation data. Comput Vis Graph Image Process 28:323-344

Peunker T, Douglas DH (1975) Detection of surface-specific points by local parallel processing of discrete terrain-elevation data. Comput Graph Image Process 4:375-387

Torwaki J, Fukumura T (1978) Extraction of structural information from grey pictures. Comput Graphics Image Process 8:30-51

Tribe A (1992) Automated recognition of valley lines and drainage networks from grid digital elevation models: a review and a new method. J Hydrol 139:263-293

Weiss A (2001) Topographic position and landforms analysis. Poster presentation, ESRI user conference, San Diego, CA 